\title{
Application of high resolution geophysical prospecting to assess the risk related to subsurface deformationin Mexico City
}

\author{
F. A. Centeno-Salas ${ }^{1,3}$, D. Carreón-Freyre ${ }^{2}$, W. A. Flores-García ${ }^{3}$, R. I. Gutiérrez-Calderón ${ }^{3}$, and \\ E. Luna-Sánchez ${ }^{1}$ \\ ${ }^{1}$ Posgrado en Ciencias de la Tierra, Universidad Nacional Autónoma de México (UNAM), Mexico City, Mexico \\ ${ }^{2}$ Laboratorio de Mecánica Geosistemas (LAMG), Centro de Geociencias, UNAM, Querétaro, Mexico \\ ${ }^{3}$ Centro de Evaluación de Riesgo Geológico (CERG), Delegación Iztapalapa del Distrito Federal, Mexico
}

Correspondence to: D. Carreón-Freyre (freyre@geociencias.unam.mx)

Published: 12 November 2015

\begin{abstract}
In the eastern sector of Mexico City the sub soil consists of high contrasting sequences (lacustrine and volcanic inter bedded deposits) that favor the development of erratic fracturing in the surface causing damage to the urban infrastructure. The high-resolution geophysical prospecting are useful tools for the assessment of ground deformation and fracturing associated with land subsidence phenomena.

The GPR method allowed to evaluate the fracture propagation and deformation of vulcano-sedimentary sequences at different depths, the main electrical parameters are directly related with the gravimetric and volumetric water content and therefore with the plasticity of the near surface prospected sequences. The active seismology prospection consisted in a combination of Seismic Refraction (SR) and Multichannel Analysis of Surface Waves (MASW) for the estimation of the velocity of the mechanical compressive (P) and the shear (S) waves. The integration of both methods allowed to estimate the geomechanical parameters characterizing the studied sequence, the Poisson Ratio and the volumetric compressibility.

The obtained mechanical parameters were correlated with laboratory measured parameters such as plasticity index, density, shear strength and compressibility and, GPR and seismic profiles were correlated with the mapped fracture systems in the study area. Once calibrated, the profiles allowed to identify the lithological contact between lacustrine and volcanic sequences, their variations of thicknesses in depth and to assess the deformation area in the surface. An accurate determination of the geometry of fracturing was of the most importance for the assessment of the geological risk in the study area.
\end{abstract}

\section{Introduction}

The ground-fracturing phenomenon related with land subsidence has increased recently in Mexico City due to natural and anthropogenic processes. One of the areas with the highest differential subsidence is the lacustrine plain of Iztapalapa (Carreón-Freyre, 2011). The high-resolution geophysical prospecting, such as Ground Penetrating Radar (GPR) and active seismology, are useful tools for the assessment of ground deformation. In the eastern sector of Mexico City the sub soil consists of high contrasting sequences (lacustrine and volcanic inter bedded deposits) that favor the development of erratic fracturing in the surface causing damage to the urban infrastructure.

The GPR method is based on the generation of short electromagnetic pulses generated by a transmitter that penetrate in the subsoil, and are reflected according with the properties of optics laws, toward the receiving antenna. This method allowed to evaluate the fracture propagation and deformation of vulcano-sedimentary sequences at different depths (Daniels et al., 1998). By the use of the Common Mid Point (CMP) arrangement was possible to measure the propagation velocity of electromagnetic waves through the contrasting layers and allowed to build high-resolution geological 


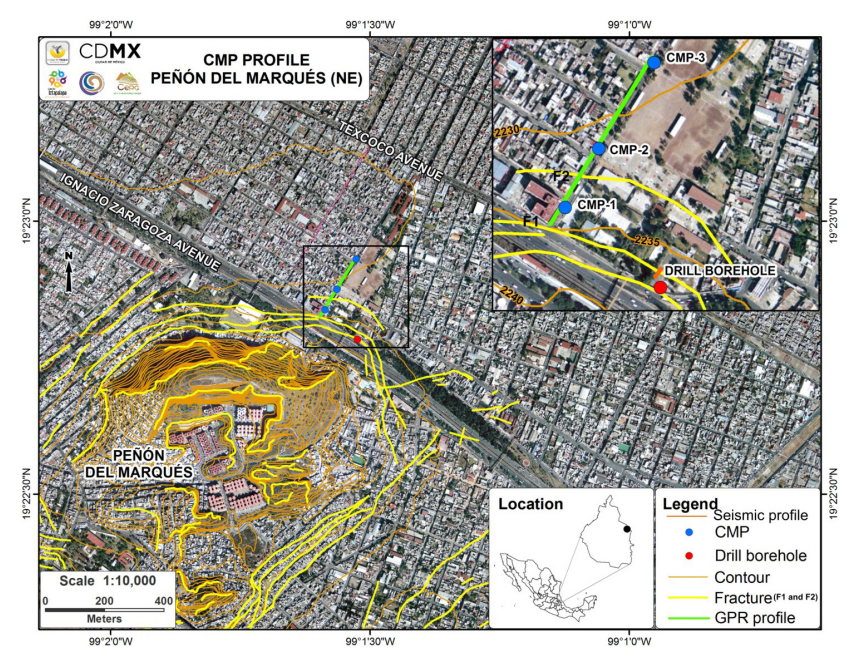

Figure 1. Location of the study area, east of Mexico City with spatial distribution of ground-fracturing and geophysical study.

sections (Grandjean et al., 2000). The energy is reflected to the surface by the contrasting electrical properties of each lithological sequence; the main electrical parameters are dielectric constant, $\varepsilon$, the magnetic permeability, $\mu$, and the electrical conductivity, $\sigma$, which are directly related with the gravimetric and volumetric water content and therefore with the plasticity.

The MASW seismic method allows the record of the surface waves generated by a mechanical source in the surface (hammer) by the analysis of the dispersion curve of the fundamental mode, and eventually the higher modes. This curve can be inverted in a vertical section of shear strength because the surface waves are directly related by a factor of 0.97 with shear wave moreover, these take usually $70 \%$ of the total seismic energy. The active seismology prospection consisted in a combination of Seismic Refraction (SR) and Multichannel Analysis of Surface Waves (MASW) for the estimation of the velocity of the mechanical compressive (P-) and the shear (S-) waves. The variation in depth of the shear velocity of seismic waves is directly related with some mechanical parameters of the prospected sequence such as: bulk modulus, Young's modulus, shear modulus and Poisson's ratio, used for the estimation of their deformation and potential fracturing.

\section{High-resolution geophysical studies: GPR and MASW}

The study area is located in the Basin of Mexico, east of the city, within a transition zone between volcanic and lacustrine materials (Fig. 1). The volcanic deposits come from a volcanic cone called "Peñón del Marques" composed by pyroclastic rocks and lava. Lake sediments are mainly clays, with large amounts of water content retained in their struc-

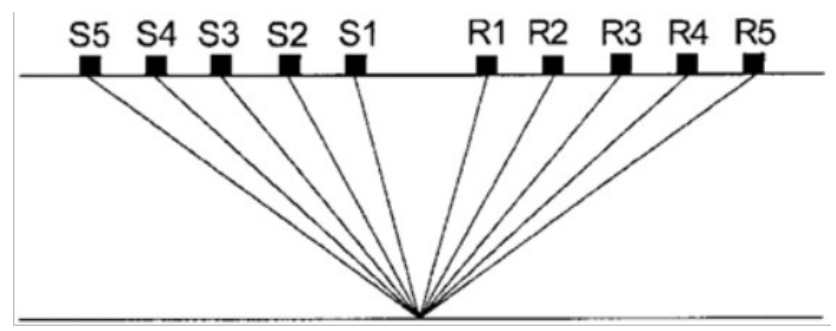

Figure 2. Common Mid Point (CMP) acquisition technique, where "S" denotes the transmitter location and " $\mathrm{R}$ " denotes the receiver location (Huisman, 2003).

ture and with high plasticity values. The geophysical profiles were acquired at the base of the volcanic structure, over a high deformed and fractured area. GPR and seismic profiles are parallel, separated by $50 \mathrm{~m}$. In the same area a geotechnical borehole was drilled for the characterization of the lithological sequence. In Fig. 1 the location of the study area is shown.

\subsection{GPR prospecting}

GPR fundamentals are based in the electromagnetic induction, where time is a decisive variable in conjunction with the spatial coordinates $x, y, z$. The induction field is of the same frequency as the transmitter current and varies in time within the prospected media, following electromagnetic laws, it creates secondary currents emerging from the prospected media to be measured by a receiver (Nabighian, 1988).

This is a high resolution method because it is capable to get 64 samples per meter, allowing to identify areas of deformation and fracture by reflection profiles. The Common Mid Point (CMP) technique was used to estimate the propagation velocity of the electromagnetic waves in different media and allowed the estimation of other physical properties. The CMP technique consists on separating the transmitter and receiver at different constant distances, as shown in Fig. 2. Three CMP profiles were acquired to characterize the spatial variation of the geological materials by the analysis of their velocity. Figure 3 shows the field data, processing, and interpretation of velocities from CMP. A GPR profile of $200 \mathrm{~m}$ length (radargram) was acquired complement the punctual measurements. The radargram shown in Fig. 4 was acquired

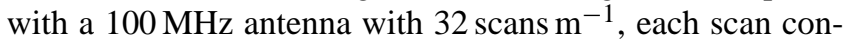
tains 1024 samples. The horizontal resolution is about $3 \mathrm{~cm}$ and the vertical resolution is less than $1 \mathrm{~cm}$. This resolution allowed the characterization of the lithological variations related with the deformation and fracturing of the studied sequence through the change in the waveform.

The radargram shows three main layers: (a) a layer of volcanic sand $2 \mathrm{~m}$ width; (b) a lacustrine layer corresponding to clayey materials of variable thickness; and (c) a pyroclastic deposit is the subspace corresponding to volcanic sand until $10 \mathrm{~m}$ depth. The radargram shows a distortion of the se- 
(a)

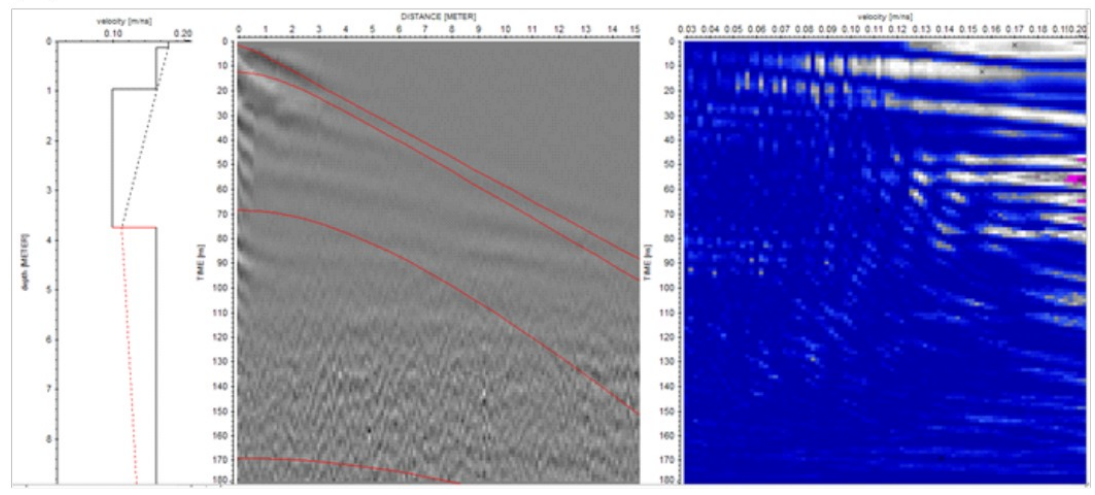

(b)
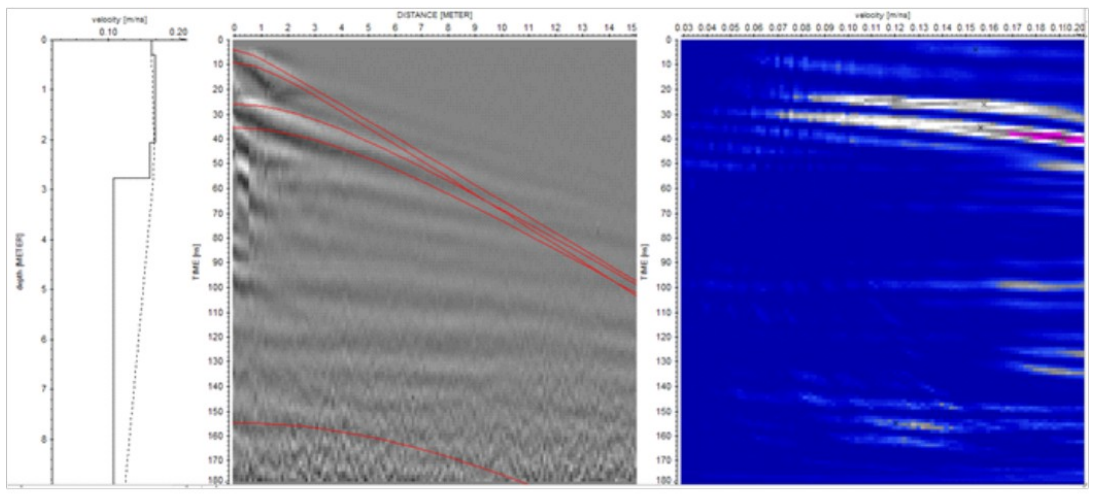

(c)
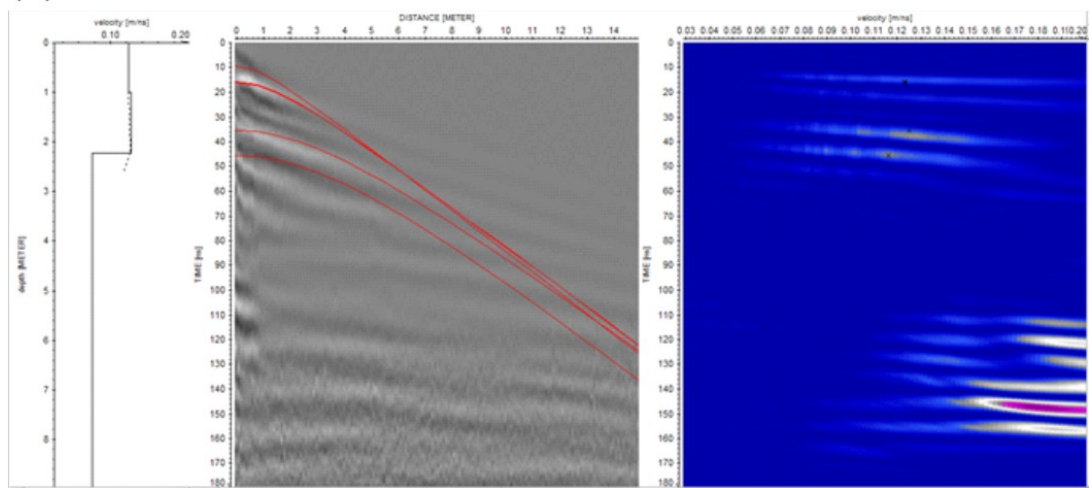

Figure 3. Data and results of the three CMP, on the left side the velocity, the field data on central side, and the processing on right side. (a) First CMP; (b) second CMP; (c) third CMP.

quence because of the high plasticity of the clayey materials, and fracturing recorded in the lower sandy layer.

\subsection{MASW and Refraction Seismic (SR) profiles}

The MASW method deals with surface waves in the low frequencies $(1-30 \mathrm{~Hz})$ and uses a shallow range of investigation (approximately $20 \mathrm{~m}$ depth). These superficial waves are related with S-wave by a factor of 0.97 . Shear velocity is di- rectly linked to the material stiffness and is one of the most critical mechanical parameters. The shear-wave velocity $\left(V_{\mathrm{s}}\right)$ is the best indicator for the detection of fracture zones because of the dramatic decrease of velocities.

The SR method involves the analysis of the travel times of first wave arrivals through the prospected layer to surface. The interpretation of the seismic data involves resolving the number of layers of the sequence, according to the velocity 
(a)

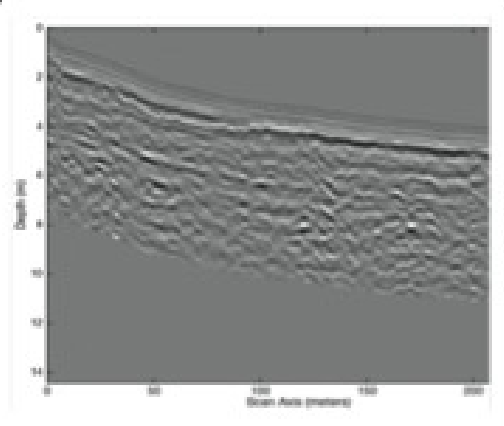

(b)

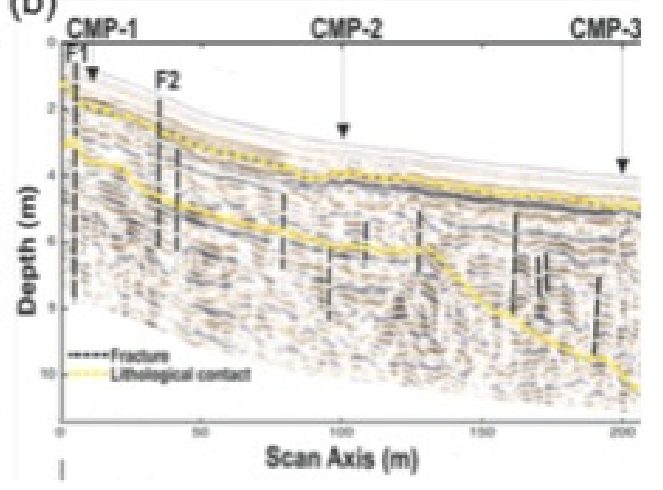

Figure 4. Reflection Profile of GPR. (a) Profile without geological interpretation; (b) profile with geological interpretation and CMP data correlation.

Table 1. Mechanical properties inferred from wave velocities of body.

\begin{tabular}{lccccccc}
\hline Lithologhy & $\begin{array}{c}\text { P-wave velocity } \\
\left(\mathrm{m} \mathrm{s}^{-1}\right)\end{array}$ & $\begin{array}{c}\text { S-wave velocity } \\
\left(\mathrm{m} \mathrm{s}^{-1}\right)\end{array}$ & $\begin{array}{c}\text { Bulk module } \\
\left(\mathrm{kg} \mathrm{cm}^{-2}\right)\end{array}$ & $\begin{array}{c}\text { Shear module } \\
\left(\mathrm{kg} \mathrm{cm}^{-2}\right)\end{array}$ & $\begin{array}{c}\text { Young module } \\
\left(\mathrm{kg} \mathrm{cm}^{-2}\right)\end{array}$ & $\begin{array}{c}\text { Poisson } \\
\text { module }\end{array}$ & $\begin{array}{c}\text { Water } \\
\text { content }(\%)\end{array}$ \\
\hline $\begin{array}{l}\text { Volcanic } \\
\text { sequence }\left(\mathrm{L}_{1}\right)\end{array}$ & 500 & 270 & $65000-90000$ & $20000-34000$ & $180000-260000$ & $0.04-0.16$ & $11-47$ \\
$\begin{array}{l}\text { Volcanic } \\
\text { sequence }\left(\mathrm{L}_{2}\right)\end{array}$ & $280-400$ & $90-180$ & $15000-30000$ & $15000-30000$ & $100-600000$ & 0.48 & $226-258$ \\
$\begin{array}{l}\text { Volcanic } \\
\text { sequence }\left(\mathrm{L}_{3}\right)\end{array}$ & $480-552$ & 300 & $6500-90000$ & $65000-90000$ & $180000-260000$ & $0.04-0.16$ & $14-50$ \\
\hline
\end{tabular}

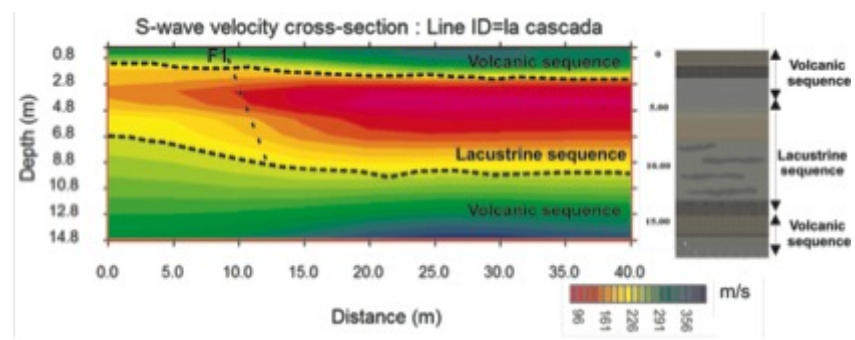

Figure 5. S-wave model, acquired from MASW method and a stratigraphic correlation with the borehole.

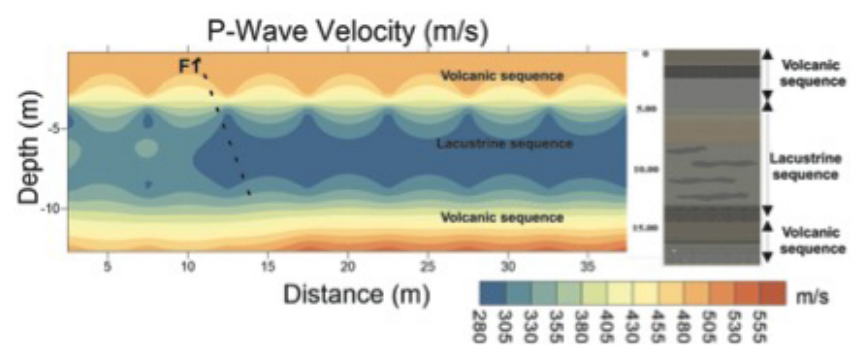

Figure 6. P-wave model, acquired from the determination of the first arrivals method and a stratigraphic correlation with the borehole. SR Method.

variation of each layer, and the travel-time from a given refractor to the ground surface.
MASW and SR profiles were acquired using 16 geophones of $12.5 \mathrm{~Hz}$ acquisition frequency, spaced every $2.5 \mathrm{~m}$ with a total length of $40 \mathrm{~m}$. The S-wave velocity is determined by analyzing the Rayleigh wave and, P-wave velocity by calculating the first arrivals. Figures 5 and 6 show the S-wave model and $\mathrm{P}$-wave model respectively. In Table 1 the relationship of $\mathrm{P}$-wave and $\mathrm{S}$-wave velocity is presented.

The rate of the two body waves ( $\mathrm{P}$ and $\mathrm{S}$ ) determine the spatial distribution of the different mechanical parameters. Equation (1) describe the compression waves and Eq. (2) the shear wave.

$$
\begin{aligned}
& V_{\mathrm{p}}=\sqrt{\frac{\lambda+2 \mu}{\rho}} \\
& V_{\mathrm{s}}=\sqrt{\frac{\mu}{\rho}},
\end{aligned}
$$

with $\lambda=\kappa-\frac{2}{3} \mu$.

The parameter $\lambda$ is known as the first Lamé constant, which has no physical sense. The $V_{\mathrm{p}}$ and $V_{\mathrm{s}}$ parameters are the $\mathrm{P}$-wave and $\mathrm{S}$-wave velocities, $\mu$ is the modulus of rigidity (or shear), $\kappa$ is the bulk modulus (or incompressible) and $\rho$ is the density. These mechanical parameters result from the theoretical basis of the dynamic elasticity that studies the behavior of a solid upon the application of a force, both compression and shear, in one or in all three spatial dimen- 

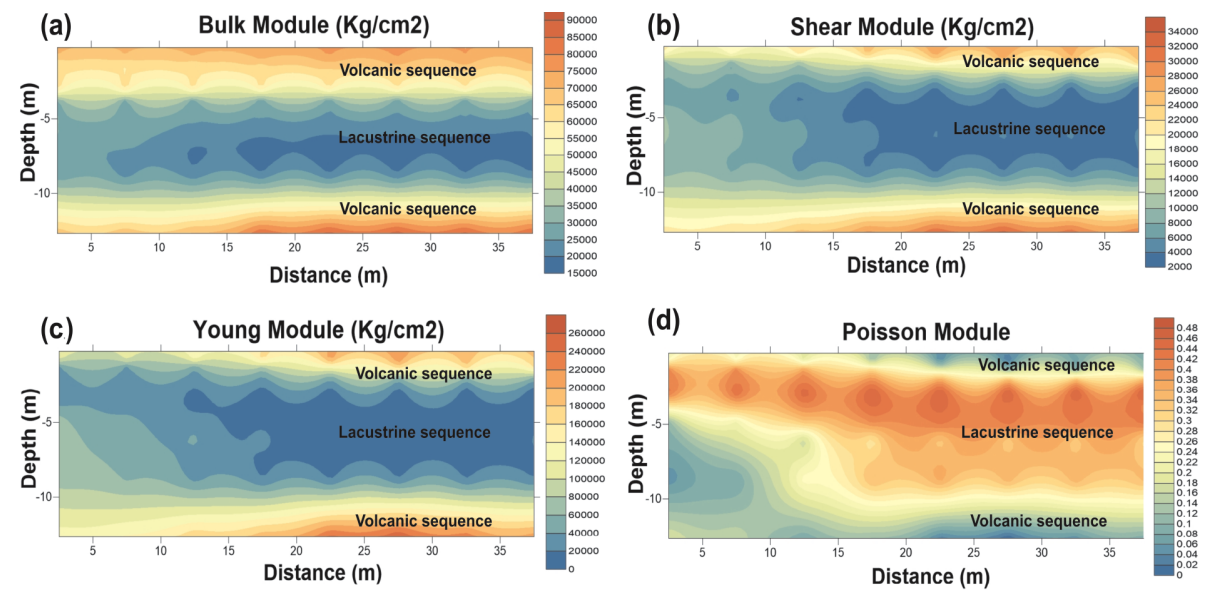

Figure 7. Distribution of mechanical parameters obtained from modeling of the P- and S-wave (SR Method): (a) spatial model of Bulk module; (b) spatial model of shear modulus; (c) spatial model of Young's modulus; (d) model spatial of Poisson constant.

Table 2. Velocities obtained from the CMP data.

\begin{tabular}{lcc|cc|cc}
\hline Lithologhy & \multicolumn{2}{c|}{ CMP-1 Depth velocity } & \multicolumn{2}{c|}{ CMP-2 Depth velocity } & \multicolumn{2}{c}{ CMP-2 Depth velocity } \\
\cline { 2 - 7 } & $(\mathrm{m})$ & $\left(\mathrm{m} \mathrm{ns}^{-1}\right)$ & $(\mathrm{m})$ & $\left(\mathrm{m} \mathrm{ns}^{-1}\right)$ & $(\mathrm{m})$ & $\left(\mathrm{m} \mathrm{ns}^{-1}\right)$ \\
\hline Volcanic sequence $\left(\mathrm{L}_{1}\right)$ & $0-1$ & 0.16 & $0-2.8$ & 0.15 & $0-2.3$ & 0.13 \\
Volcanic sequence $\left(\mathrm{L}_{2}\right)$ & $1-3.8$ & 0.085 & 2.8 & 0.09 & 2.3 & 0.05 \\
Volcanic sequence $\left(\mathrm{L}_{3}\right)$ & 3.8 & 0.16 & - & - & - & - \\
\hline
\end{tabular}

sions (Velis, 2007). Seismic velocities are directly related with these mechanical properties for a prospected media.

The bulk modulus, rigidity, and Young modulus, can be determined either from static or dynamic experiments, involving the travelling of seismic waves through the soil. The bulk modulus of a soil measures the resistance to uniform compression. It is defined as the ratio of the infinitesimal pressure increase to the resulting decrease of the volume. The shear modulus is the coefficient of elasticity for a shearing force. It is defined as the ratio of shear stress to the unit displacement per sample length. Mathematically is the tangential force exerted and the related strain change. The elastic constant, called the Poisson's ratio $(\sigma)$ measure the compressibility of a material perpendicular to the applied stress, or the ratio of vertical and horizontal strains. This can be expressed in terms of properties measured in the field, as velocities of P-waves and S-waves and in terms of $\mu$ and $\lambda$, as shown below (Aki, 2002).

$$
\sigma=\frac{\lambda}{2(\lambda+\mu)}
$$

with

$$
\begin{aligned}
\mu & =V_{\mathrm{s}}^{2} \rho ; \quad \lambda=V_{\mathrm{p}}^{2} \rho-2 \mu=V_{\mathrm{p}}^{2} \rho-2 V_{\mathrm{s}}^{2} \rho \\
\sigma & =\frac{V_{\mathrm{p}}^{2} \rho-2 V_{\mathrm{s}}^{2} \rho}{2\left(V_{\mathrm{p}}^{2} \rho-2 V_{\mathrm{s}}^{2} \rho+V_{\mathrm{s}}^{2} \rho\right)}
\end{aligned}
$$

$$
\begin{aligned}
& =\frac{V_{\mathrm{p}}^{2}-2 V_{\mathrm{s}}^{2}}{2\left(V_{\mathrm{p}}^{2}-2 V_{\mathrm{s}}^{2}\right)} \\
& =\frac{\left(V_{\mathrm{p}} / V_{\mathrm{s}}\right)^{2}-2}{2\left(V_{\mathrm{p}} / V_{\mathrm{s}}\right)^{2}-2} .
\end{aligned}
$$

If $V_{\mathrm{s}}$ is small then Poisson's ratio equals 0.5, indicating either a fluid, because shear waves do not pass through fluids, or a material that maintains constant volume regardless of stress, also known as an ideal incompressible material.

The Young modulus, $E$, describes the elastic properties of a solid undergoing tension or compression in only one direction. Young's modulus is a measure of the ability of a material to withstand changes in length when under lengthwise tension or compression (see Eq. 5).

$E=3 \kappa(1-2 \sigma)$

If seismic data are available, the spatial distribution of mechanical parameters of the prospected sequence can be modeled to create pseudo-geologic sections as shown in Fig. 7. The distribution of the obtained mechanical parameters $(\kappa$, $\mu, \sigma$ and $E$ ) was correlated with the log of the studied sequence and with physical measurements from borehole samples.

The Poisson constant distribution, varying from 0.38 to 048 , and S-wave velocities, varying from 90 to $180 \mathrm{~m} \mathrm{~s}^{-1}$, are correlated with the lacustrine layer having the larger water content, approximately $200 \%$, in the sequence. The low 
values of $E$ modulus, $\kappa$ modulus and $\mu$ modulus show that the lacustrine material is highly deformable (i.e. low bearing capacity). The volcanic sand layer shows higher values of $\kappa$, $\mu$ and $E$, less deformable, having lower water content values, $30 \%$ in average.

The distribution of the mechanical parameters (Fig. 7 and Table 2) also allowed identifying the transition zone by the increase the thickness of the lacustrine sequence which contact correspond to the location of fracture $F_{1}$.

\section{Conclusions}

The results of applying the GPR, MASW and SR methods simultaneously show the persistence of the clayey lacustrine material with variable thickness encased by volcanic materials. This material was characterized in the laboratory a present gravimetric large water contents varying from 200 to $300 \%$.

The contrasting mechanical properties between the two types of material may cause slippage over lithological contacts, causing the propagation of deformation and fracturing of the sequence, as shown in the GPR profile of Fig. 4. This can also be correlated with the distribution of the S-wave velocities presented in Fig. 5, where the lower values (about $100 \mathrm{~m} \mathrm{~s}^{-1}$ ) corresponds to the location of fracture $F_{1}$.

The application of seismology and electromagnetic high resolution methods allow to characterize deformation and fracturing in a subsidence area. GPR studies allowed the monitoring of the deformation zone and fracturing and to correlate lithological variations through CMP profiles. Seismology shows to be very useful to quantify the mechanical behavior of the studied sequences.

The physical and mechanical parameters of the high deformability of the lacustrine sequence showing large water content and low shear strength. Fracturing showed to be strongly related with the lithological contact between materials having contrasting mechanical parameters in heterogeneous subsidence areas such as the east zone of Mexico City.
Acknowledgements. The authors thank his colleagues at the Centre for Evaluation of Geological Risk and the Center of Geosciences for the field support and technical suggestions for improving this article. The authors acknowledge the support of the DGAPA-UNAM research project No. IN114714.

\section{References}

Aki, K. and Richards, P.: Quantitative seismology: theory and methods: W. H. Freeman and Co. University Science Book, 2nd Edn., 67-288, 2002.

Carreón-Freyre, D.: Identificación y Caracterización de los Diferentes Tipos de Fracturas que Afectan el Subsuelo de la Delegación Iztapalapa en el Distrito Federal, Informe Técnico, Ingeniería Geologica, AI México, 3-9, 2011.

Daniels, D., Gunton, D., and Scott H.: Introduction to subsurface radar, IEEE Proceedings, 135, 278-320, 1998.

Grandjean, G., Gourry, J., and Bitri, A.: Evaluation of GPR techniques for civil-engineering applications: study on a test site, J. App. Geophys., 45, 141-156, doi:10.1016/S09269851(00)00021-5, 2000.

Huisman, J., Hubbard, S., Redman, J., and Anna, P.: Measuring Soil Water Content with Ground Penetrating Radar: A Review, Vadose Zone J., 2, 476-491, 2003.

Nabighian, N.: Electromagnetic Methods in Applied Geophysics: Theory, Society of Exploration Geophysics, Tulsa, OK, USA, 1, 131-141, 1998.

Velis, D.: Improved AVO fluid detection and lithology discrimination using Lame petrophysical parameters " $\lambda \rho$ ", " $\mu \rho$ ", and " $\lambda / \mu$ fluid stack" from P and S inversions, 67tn Annual International Meeting, SEG, Expanded Abstracts, 183-186, 1997. 